\title{
Do invasive alien plants benefit more from global environmental change than native plants?
}

\author{
YANJIELIU ${ }^{1,2 *}$, AYUB M. O. ODUOR ${ }^{1,3, *}, \mathrm{ZHEN} \mathrm{ZHANG}^{4 *}, \operatorname{ANTHONYMANEA}^{5}$, \\ IFEANNA M. TOOTH ${ }^{6}$, MICHELLER. LEISHMAN ${ }^{5}$, XINGLIANG XU $^{2}$ and MARK VAN \\ KLEUNEN $^{1}$ \\ ${ }^{1}$ Ecology, Department of Biology, University of Konstanz, Universitätsstrasse 10, D-78457 Konstanz, Germany, ${ }^{2}$ Key Laboratory \\ of Ecosystem Network Observation and Modeling, Institute of Geographic Sciences and Natural Resources Research, Chinese \\ Academy of Sciences, 11A Datun Road, Chaoyang District, Beijing 100101, China, ${ }^{3}$ Department of Applied and Technical Biology, \\ Technical University of Kenya, P.O. Box 52428-00200, Nairobi, Kenya, ${ }^{4}$ School of Resources and Environment, Anhui \\ Agricultural University, No. 130 Changjiang West Road, Hefei 230036, China, ${ }^{5}$ Department of Biological Sciences, Macquarie \\ University, North Ryde, NSW 2109, Australia, ${ }^{6}$ Royal Botanic Gardens, Sydney, NSW 2000, Australia
}

\begin{abstract}
Invasive alien plant species threaten native biodiversity, disrupt ecosystem functions and can cause large economic damage. Plant invasions have been predicted to further increase under ongoing global environmental change. Numerous case studies have compared the performance of invasive and native plant species in response to global environmental change components (i.e. changes in mean levels of precipitation, temperature, atmospheric $\mathrm{CO}_{2} \mathrm{con}-$ centration or nitrogen deposition). Individually, these studies usually involve low numbers of species and therefore the results cannot be generalized. Therefore, we performed a phylogenetically controlled meta-analysis to assess whether there is a general pattern of differences in invasive and native plant performance under each component of global environmental change. We compiled a database of studies that reported performance measures for 74 invasive alien plant species and 117 native plant species in response to one of the above-mentioned global environmental change components. We found that elevated temperature and $\mathrm{CO}_{2}$ enrichment increased the performance of invasive alien plants more strongly than was the case for native plants. Invasive alien plants tended to also have a slightly stronger positive response to increased $\mathrm{N}$ deposition and increased precipitation than native plants, but these differences were not significant ( $\mathrm{N}$ deposition: $P=0.051$; increased precipitation: $P=0.679$ ). Invasive alien plants tended to have a slightly stronger negative response to decreased precipitation than native plants, although this difference was also not significant $(P=0.060)$. So while drought could potentially reduce plant invasion, increases in the four other components of global environmental change considered, particularly global warming and atmospheric $\mathrm{CO}_{2}$ enrichment, may further increase the spread of invasive plants in the future.
\end{abstract}

\section{Introduction}

Across the globe, thousands of plant species have been introduced to biogeographic regions where they are not native (van Kleunen et al., 2015). Some of these introduced plants have since become naturalized, and eventually invasive, whereby they displace native plants and hence threaten native diversity, disrupt ecosystem functions and services, and cause large economic damage (Pimentel et al., 2005; Vilà et al., 2011). Consequently, understanding the mechanisms by which invasive alien plant species outperform native plants in the recipient native communities has become a hot topic in ecology (Funk \& Vitousek, 2007; van Kleunen et al., 2010; Leishman et al., 2010; Heberling \& Fridley, 2013). With ongoing global environmental change, there is also increasing interest in how the spread of invasive plants may change in the future (Dukes \& Mooney, 1999; Bradley et al., 2010a; Jia et al., 2016).

Biotic exchange is itself a major component of global environmental change, but it might be strongly affected by other global change components such as increasing atmospheric $\mathrm{CO}_{2}$ concentrations, increasing temperatures, increasing nitrogen $(\mathrm{N})$ deposition, and increasing or decreasing precipitation. It is thought that these environmental changes are more likely to promote than to inhibit invasive plant performance compared to native plant performance. This is because invasive 
plants often exhibit broad environmental tolerance and high phenotypic plasticity, which may confer the capacity to survive in altered environmental conditions (Richards et al., 2006; Davidson et al., 2011). Furthermore, the intrinsically high growth rate characteristic of many invasive plant species (Grotkopp et al., 2010; van Kleunen et al., 2010; Dawson et al., 2011) may enable them to respond more positively to environmental changes that result in increased resource availability (elevated levels of water supply, atmospheric $\mathrm{CO}_{2}$ concentrations and $\mathrm{N}$ deposition) than native plants adapted to low resource conditions (Tilman, 2004). Thus, global environmental change could further promote invasiveness of invasive alien plant species.

The hypothesis that global environmental change may favour performance of invasive plant species more strongly than that of native plants has been subjected to numerous experimental tests. These are usually case studies involving local comparisons of a single pair or a few pairs of invasive and native plant species, and have produced mixed results (Dukes \& Mooney, 1999; Bradley et al., 2010a). A few years ago, Sorte et al. (2013) did a meta-analysis on the responses of naturalized alien and native organisms to climate change. Across different types of organisms and ecosystems, naturalized alien species tended to show stronger responses than natives, but, among terrestrial plants, naturalized alien and native plants showed similar responses. That study, however, was not restricted to invasive alien plant species and did not correct for phylogenetic nonindependence of the studied species. Although Sorte et al. (2013) included many different types of organisms and ecosystems, they did not consider responses to $\mathrm{N}$ deposition, which is another major component of global environmental change (Holland et al., 2005; Liu et al., 2013). Successful plant species are often associated with a particular suite of traits that enable them to respond more positively to $\mathrm{N}$ deposition (Dawson et al., 2012). Therefore, one could hypothesize that invasive plants are more successful in areas with high $\mathrm{N}$ deposition. Indeed, several studies found evidences in support of this hypothesis at a regional scale (Scherer-Lorenzen et al., 2000, 2007; Seabloom et al., 2015). Moreover, a previous meta-analysis also found evidence that in terrestrial plants, invasive species responded more strongly to $\mathrm{N}$ deposition than native species (Gonzalez et al., 2010). However, that meta-analysis did not correct for phylogenetic nonindependence of the studied species either. Recent studies have shown that inclusion of phylogenetic information can significantly change the outcomes of a meta-analysis (Chamberlain et al., 2012), and hence correction for species relatedness should be an important component of any meta-analysis on variation among species.
Here, we established a database, restricted to plants, with responses of invasive alien and native species to environmental change. We used these data to do a phylogenetically controlled meta-analysis to address the question: (i) Do invasive alien plant species respond more positively (i.e. benefit more) to each component of global environmental change than native plant species? (ii) Which components of global environmental change are likely to favour or inhibit performance of invasive alien plants over native plants? Answering these questions will enable an assessment of whether global environmental change is likely to further increase invasiveness of invasive alien plants and thereby may exacerbate their impacts on native plants in the future.

\section{Materials and methods}

\section{Data compilation}

To identify studies on performance responses of both native and invasive alien plants to global change, we conducted a literature search for peer-reviewed publications in ISI Web of Science (http://apps.webofknowledge.com/) and Google Scholar using the following search string: 'climate change' OR 'global change' OR 'warm*' OR 'temperature' OR 'nitrogen' $\mathrm{OR}$ 'nitrogen deposition' $\mathrm{OR}$ ' $\mathrm{CO}_{2}$ ' $\mathrm{OR}$ 'carbon dioxide' $\mathrm{OR}$ 'precipitation' OR 'watering' OR 'drought' OR 'rainfall' AND 'invasive' OR 'alien' OR 'non-native'. All published records from 1980 to 30th June 2015 were included in the search. We found two pre-1980 studies on temperature responses of native and invasive species (i.e. Henry \& William, 1958; Ashby \& Hellmers, 1959), but, as these studies did not provide measures of variation (standard errors or standard deviations), they could not be used for the meta-analysis. We also included studies published in the Chinese language (www.cnki.net). Our searches were limited to studies on plants and resulted in 1036 publications.

We then individually assessed each publication and retained the ones that met each of the three criteria given below. (i) The publication reported effects of manipulating mean values of at least one of the five different components of global environmental change (i.e. increases in temperature, atmospheric $\mathrm{CO}_{2}$ concentration, $\mathrm{N}$ deposition, increased precipitation or a decrease in precipitation) on performance of invasive alien and native plants. Although global environmental change also entails changes in variability, such as the increased frequency of extremes in temperature and precipitation, we focus on changes in means values because only few studies have manipulated variability in global change components. (ii) Publications included at least one invasive alien and one native plant species in the same experiment (origin and invasive status of each species was determined from the respective publications). (iii) Publications reported mean values, sample sizes and variances for performance-related traits of each species. The performance-related traits included in our meta-analysis were direct estimates of fitness (i.e. survival and reproduction), of growth (i.e. biomass and size) and 
physiology (i.e. photosynthetic rate, which is likely to increase the performance of plants). In total, 56 publications met these criteria (see Materials and Methods S1), covering 74 invasive alien species and 117 native species. There were a few studies in which it was not clear whether the alien species studied was invasive or not. Such studies were excluded from the analysis presented in the main text. However, analysis with and without data from such studies gave similar results (Tables S1 and S2, Figs S1 and S2). We also considered whether seeds of invasive species were sourced from their native range or their invaded range, as this might influence the performance of plants. Although not all studies provided information on this, seeds of the invasive species appear to be generally sourced from the invaded range. Therefore, the effect of seeds source could not be tested.

We extracted mean values of the performance-related traits mentioned above and their corresponding variances (standard deviations, standard errors or 95\%-confidence intervals) and sample sizes directly from the text or tables, or from figures using the software IMAGE J 1.47v (Rasband, 2013). For all cases of temperature, atmospheric $\mathrm{CO}_{2}$ concentration and soil $\mathrm{N}$, we considered the ambient level (i.e. no treatment level) of an environmental change factor as the 'control', and the elevated level of the same factor as the 'treatment'. However, as precipitation is likely to decrease in some parts of the world and increase in other parts, some studies imposed a drought treatment, whereas others increased watering relative to ambient levels. We considered these as two different types of studies. For studies with decreased water availability relative to ambient, the drought treatment is considered the 'treatment', and for studies with increased water availability relative to ambient, the high water availability treatment is considered the 'treatment'. When performance measures were reported for different time points from the same experiment, we only used the data from the last time point (i.e. we chose the longest duration of the study). When more than one environmental change factor was manipulated in an experiment, we used the performance measures corresponding to manipulation of a single focal global environmental change factor, when the other factors were kept at their ambient levels. When the plants were grown under different levels of competition, we included data for all the competition levels (eight of 56 total publications in our meta-analysis manipulated competition).

\section{Effect size and variance computation}

To examine the effects of global environmental change on native and invasive alien plant performance, we calculated the $\log$ response ratio $(\ln R)$ as the effect size of response variables for each individual performance-related traits of each species per study, following Hedges et al. (1999):

$$
\ln R=\operatorname{Ln}\left(\frac{\bar{X}_{\mathrm{t}}}{\bar{X}_{\mathrm{c}}}\right)=\ln \left(\bar{X}_{\mathrm{t}}\right)-\ln \left(\bar{X}_{\mathrm{c}}\right) .
$$

Here, $\bar{X}_{\mathrm{t}}$ and $\bar{X}_{\mathrm{c}}$ are the mean values of each individual trait measure in the treatment (t) and control (c), respectively. An $\ln R$ value $<0$ indicates a decrease in plant performance in response to a change in the environmental change factor; a value $>0$ indicates an increase in plant performance. The variance of $\ln R$ was calculated, following Hedges et al. (1999) as

$$
v_{\ln R}=\frac{\left(\mathrm{SD}_{\mathrm{c}}\right)^{2}}{N_{\mathrm{c}}\left(\bar{X}_{\mathrm{c}}\right)^{2}}+\frac{\left(\mathrm{SD}_{\mathrm{t}}\right)^{2}}{N_{\mathrm{t}}\left(\bar{X}_{\mathrm{t}}\right)^{2}} .
$$

Here, $N_{\mathrm{t}}, N_{\mathrm{c}}, \mathrm{SD}_{\mathrm{t}}, \mathrm{SD}_{\mathrm{c}}, \bar{X}_{\mathrm{t}}$, and $\bar{X}_{\mathrm{c}}$ are sample sizes, standard deviations and mean values for traits measured in the treatment and control, respectively. Because some studies reported different measures of performance-related traits for the same plant species, we pooled the multiple effect sizes (weighted by the inverse variance) and corresponding variances per study to avoid pseudoreplication (Leimu et al., 2006). Pooling was done using the fixed-effect model (using the rma function in $\mathrm{R}$ package METAFOR), because we assumed that there is a single, true underlying effect size per species in a study (Borenstein et al., 2009). The resulting 252 effect sizes and corresponding mean variances were used in the analyses described below.

\section{Data analysis}

All meta-analytical calculations and statistical analyses were performed in $\mathrm{R}$ 3.1.3 (R Core Team, 2015) using the package METAFOR v1.9-7 (Viechtbauer, 2010). First, to test whether the plants, on average, exhibited significant positive or negative responses to environmental change regardless of their invasive status, we performed a general meta-analysis using a random-effects model (i.e. we assumed that there is true random variation among effect sizes, as is thought to be the case for ecological data; Gurevitch \& Hedges, 2001). Then, to test whether native and invasive alien plants differed significantly in their performance responses to each of the different components of global environmental change (increases in mean levels of precipitation, temperature, atmospheric $\mathrm{CO}_{2}$ levels or $\mathrm{N}$ deposition, or a decrease in mean levels of precipitation) separately, we constructed mixed-effects multivariate models using the rma.mv function. In the models, plant invasive status was included as a fixed-effects moderator. Other fixed-effects moderators were also considered but either had insufficient data, no variance or did not affect the results and so were not presented in this study. Because some studies included multiple pairs of invasive alien and native plant species, yielding multiple effect sizes per study, and some plant species were used in multiple studies, we included study (i.e. publications from which we extracted the data) and species identity as random factors in the models above.

To control for possible nonindependence of effect sizes from species with shared evolutionary history, we also included phylogenetic relatedness among the study species in the models above by including the variance-covariance matrix of species relatedness as an additional random factor. To get the variance-covariance matrix, we first constructed a base tree using the online program phylomatic (Webb \& Donoghue, 2005). Polytomies within this base tree were then resolved as far as possible using published molecular phylogenies (see Materials and Methods S2). The phylogenetic tree was then transformed to an ultrametric tree using the compute.brlen function in the package APE v 3.2 (Paradis et al., 2004). Finally, a variance-covariance matrix was calculated from the 
ultrametric tree, representing phylogenetic relatedness among species, using the $v c v$ function in the package APE $\mathrm{v} 3.2$.

In each model, we computed weighted mean effect sizes and $95 \%$ confidence intervals (CIs) for the moderator levels (invasive, native). We considered a mean effect size estimate to be significantly different from zero if the $95 \% \mathrm{CI}$ around the mean did not include zero. In these models, total heterogeneity $\left(Q_{\mathrm{T}}\right)$ in effect sizes can be partitioned into heterogeneity explained by the model structure $\left(Q_{\mathrm{M}}\right)$ and unexplained heterogeneity $\left(Q_{\mathrm{E}}\right)$. We used the $Q_{\mathrm{M}}$ test (Koricheva et al., 2013) to test for a significant difference in the mean effect size between native and invasive alien plant species for the moderator.

\section{Publication bias}

In many research fields, there is a bias against publishing negative results (Rosenthal, 1979). Hence, to assess whether there is evidence for a publication bias in our meta-data set, we used a funnel plot and Egger's regression. A funnel plot graphs effect sizes against standard errors and assumes that studies with the largest sample sizes will have lower standard errors, and hence will be near the average effect size, while studies with smaller sample sizes will show a larger spread on both sides of the average effect size (Koricheva et al., 2014). Deviations from this expected pattern can indicate publication bias (Koricheva et al., 2014). Positive asymmetry in a funnel plot is typically taken to indicate bias, in that studies with positive effects are published with a greater frequency than studies with negative effects (Koricheva et al., 2014). We first graphed the funnel plots using the funnel function and visually inspected funnel plots of standard errors or replicate numbers vs. standardized effect sizes for the presence of asymmetry (Egger et al., 1997; Sterne \& Egger, 2001). We then formally tested the asymmetry of funnel plots using Egger's test which is widely used for detecting publication bias (Sterne \& Egger, 2006) using the regtest function.

\section{Results}

In the analysis that did not consider the invasive status of the species, increases in mean levels of atmospheric $\mathrm{CO}_{2}$ concentration and $\mathrm{N}$ deposition had significantly positive effects on average plant performance (Table S3, Fig. S3). Increased temperatures and increased precipitation also had net positive effects on average plant performance, but these effects were not significantly different from zero (Table S3, Fig. S3). On the other hand, a decrease in the mean level of precipitation had a significantly negative effect on average plant performance (Table S3, Fig. S3). In the separate analyses for each component of global environmental change in which we considered the invasive status (invasive vs. native) of the plant species, elevated temperature and elevated atmospheric $\mathrm{CO}_{2}$ concentrations resulted in significantly larger increases in performance for invasive alien plants than for native plants (Table 1, Fig. 1). Invasive alien plants tended to have a slightly stronger positive response to increased $\mathrm{N}$ deposition and increased precipitation than native plants, but these differences were only marginally significant for $\mathrm{N}$ deposition and not significant for precipitation (Table 1, Fig. 1). On the other hand, invasive alien plants tended to have a slightly stronger negative response to decreased precipitation than native plants, and this difference was marginally significant (Table 1, Fig. 1).

Table 1 Results of a phylogenetically informed meta-analysis comparing invasive alien and native plant species for differences in response to environmental change (i.e. increased and decreased precipitation, elevated temperature, elevated atmospheric $\mathrm{CO}_{2}$ levels and nitrogen deposition)

\begin{tabular}{|c|c|c|c|c|c|c|c|c|c|c|c|}
\hline \multirow[b]{2}{*}{ Moderator } & & \multirow[b]{2}{*}{$\begin{array}{l}\text { Number of } \\
\text { Effect sizes }\end{array}$} & \multicolumn{3}{|c|}{ Effect sizes } & \multicolumn{3}{|c|}{$\begin{array}{l}\text { Random effects (variance } \\
\text { component) }\end{array}$} & \multicolumn{3}{|c|}{$Q_{M}$ tests } \\
\hline & & & Mean & $\begin{array}{l}\text { Lower } \\
95 \% \text { CI }\end{array}$ & $\begin{array}{l}\text { Upper } \\
95 \% \text { CI }\end{array}$ & Species & Phylogeny & Study & $Q_{M}$ & $\mathrm{df}$ & $P$ \\
\hline \multirow[t]{2}{*}{ Decreased precipitation } & Invasive & 14 & -0.5852 & -0.1884 & -0.9820 & 0.0038 & 0.0505 & -0.2850 & 3.4857 & 1 & 0.0619 \\
\hline & Native & 17 & -0.4619 & -0.0711 & -0.8526 & & & & & & \\
\hline \multirow[t]{2}{*}{ Increased precipitation } & Invasive & 6 & 0.3115 & -0.2688 & 0.8917 & -0.1380 & 0.0968 & 0.0596 & 0.1716 & 1 & 0.6787 \\
\hline & Native & 19 & 0.2213 & -0.2704 & 0.7131 & & & & & & \\
\hline \multirow[t]{2}{*}{ Elevated temperature } & Invasive & 20 & 0.3827 & 0.0250 & 0.7404 & 0.0438 & 0.0212 & 0.2359 & 9.4482 & 1 & 0.0021 \\
\hline & Native & 31 & 0.0775 & -0.2607 & 0.4157 & & & & & & \\
\hline \multirow{2}{*}{ Elevated $\mathrm{CO}_{2}$} & Invasive & 46 & 0.2932 & 0.1688 & 0.4175 & 0.0343 & 0.0000 & 0.0314 & 6.1477 & 1 & 0.0132 \\
\hline & Native & 45 & 0.1300 & 0.0055 & 0.2544 & & & & & & \\
\hline \multirow[t]{2}{*}{ Elevated nitrogen } & Invasive & 25 & 0.6556 & 0.3696 & 0.9416 & 0.0573 & 0.0182 & 0.1390 & 3.8164 & 1 & 0.0508 \\
\hline & Native & 29 & 0.4739 & 0.1931 & 0.7547 & & & & & & \\
\hline
\end{tabular}

The analysis was performed for each component of global change individually. In the analysis, the $Q_{\mathrm{M}}$ statistic and associated $P$ value test for a difference between invasive alien plants and native plants. A significant (or marginally significant) difference between invasive and native plants is marked in bold font. 


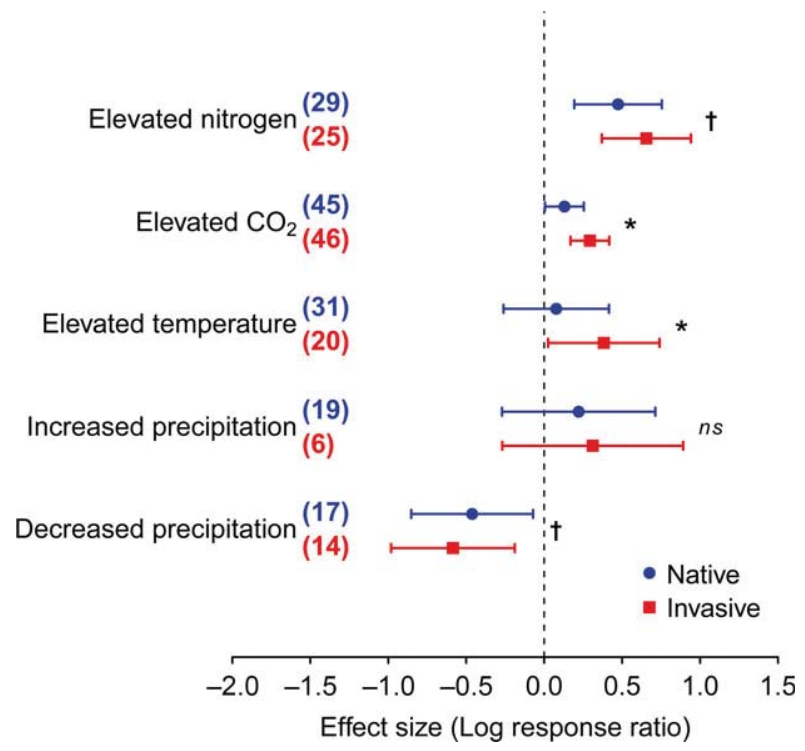

Fig. 1 Performance responses (indicated by log response ratio mean effect sizes) of native (blue symbols) vs. invasive alien plant species (red symbols) to drivers of global environmental change (increased and decreased precipitation, elevated temperature, elevated atmosphere $\mathrm{CO}_{2}$ levels and nitrogen deposition). Error bars represent 95\%-confidence intervals around the mean effect size estimates and were derived from a phylogenetically informed meta-analytic model. The asterisk $(*)$ indicates a statistically significant difference between native and invasive plant species (i.e. $P<0.05$ ), and $\dagger$ indicates a marginally significant difference (i.e. $P<0.1$ ), while $n s$ denotes no significant difference. Sample sizes (i.e. the number of effect sizes) are given in parentheses. The dashed vertical line indicates zero effect of the global environmental change drivers. [Colour figure can be viewed at wileyonlinelibrary.com]

In all analyses, the variance components associated with phylogenetic history were low (Tables 1 and S1-S3), indicating that the effect sizes used were largely phylogenetically independent. Visual inspection of the funnel plot and Egger's test for asymmetry of the funnel plot showed that the results were not significantly affected by a publication bias $(z=-0.887, \mathrm{p}=0.375$; Fig. S4).

\section{Discussion}

Many invasive alien plant species have a broader environmental tolerance and a higher phenotypic plasticity than native plants (Richards et al., 2006; Davidson et al., 2011). Hence invasive plants have been hypothesized to benefit more from global environmental change than native plants do (Dukes \& Mooney, 1999; Davidson et al., 2011). The present synthesized results of a phylogenetically controlled meta-analysis partly support this hypothesis. The separate analyses of the individual global change components showed that elevated temperature, elevated atmospheric $\mathrm{CO}_{2}$ concentrations and $\mathrm{N}$ deposition might favour performance of invasive plants relative to that of native plants. Decreased precipitation, on the other hand, might inhibit performance of invasive plants more relative to that of native plants. Our results thus suggest that particularly elevated temperature, elevated atmospheric $\mathrm{CO}_{2}$ concentrations and $\mathrm{N}$ deposition may further promote invasiveness of the invasive alien plant species, while decreased precipitation (i.e. drought) might inhibit it.

Overall, invasive plants benefited more from increases in the global environmental change components than native plants did. This result is concordant with the finding of a meta-analysis by Davidson et al. (2011) that invasive plants are more phenotypically plastic than cooccurring noninvasive plants across several different types of environmental variations. A previous meta-analysis on trait differences between invasive and noninvasive (mostly native) plant species found that, on average, invasive plant species had significantly higher values than native plants for traits reflecting physiology, size and fitness (van Kleunen et al., 2010). Combined with our results, this suggests that invasive plants may even more strongly outperform native plants under increases in global environmental changes in the future.

Our findings contrast to some extent with results of a recent meta-analysis by Sorte et al. (2013) who evaluated the responses of alien and native organisms, including both plants and animals, to elevated atmospheric $\mathrm{CO}_{2}$ concentrations, warming and changes in precipitation, in terrestrial, marine and freshwater ecosystems. They found that alien and native organisms, primarily plants, in terrestrial ecosystems did not significantly differ in their responses to environmental changes. Nevertheless, some of the patterns that we found are in line with the patterns that Sorte et al. (2013) found. The results of Sorte et al. (2013) indicate a slight tendency for stronger responses to increases in $\mathrm{CO}_{2}$ and precipitation among alien species than among native species. There are several possible explanations for why the results or the statistical significances deviate between two studies. First, we used the log response ratio (ln $R$ ) as effect size to quantify the different plastic responses to environmental changes between invasive and native plants, while Sorte et al. (2013) used the ratio of the difference between treatment and control responses to the average of responses across treatment and control conditions. Second, we only evaluated responses of plants to environmental change rather than combining plants and animals. Third, we focused on the comparison between natives and invasive aliens, while Sorte et al. (2013) compared natives with naturalized aliens, which are not necessarily invasive. Fourth, we included studies that were published after 2013 and thus were not included in Sorte 
et al. (2013). Whatever the exact reason for the discrepancies, in contrast to Sorte et al. (2013), who mainly found differences in the responses of alien and native organisms in aquatic systems, we now provide evidence that similar differences exist for terrestrial plants.

Invasive plants took significantly more advantage of $\mathrm{CO}_{2}$ enrichment than native plants did. Plants with the $\mathrm{C}_{3}$ photosynthetic pathway are thought to take more advantage of $\mathrm{CO}_{2}$ enrichment than plants with a $\mathrm{C}_{4}$ pathway (Pearcy \& Ehleringer, 1984; Poorter, 1993). Thus, the present results could also reflect differences in photosynthetic pathways between invasive and native plants in our study. However, because invasive and native plants had similar numbers of species characterized by $\mathrm{C}_{3}$ (invasive: $n=35$; native: $n=35$ ) and $\mathrm{C}_{4}$ (invasive: $n=4$; native: $n=7$ ) photosynthetic pathways in our analysis, the photosynthetic pathway likely played little role in differences between invasive and native plant responses to $\mathrm{CO}_{2}$ enrichment. Therefore, increased $\mathrm{CO}_{2}$ concentration likely favoured performance of invasive plants over native plants through direct (enhanced growth rate) and indirect (enhanced resource capture) mechanisms regardless of photosynthetic pathway.

Elevated temperature had stronger positive effects on performance of invasive plant species than of native plant species. Warming can directly affect photosynthesis and resource uptake (Llorens et al., 2004; Blumenthal et al., 2013), increase the duration of the growth period of a plant (Peñuelas et al., 2002) and could also induce a higher soil nutrient availability through increased mineralization (Rustad et al., 2001). Generally, native plants have a long evolutionary history under ambient temperatures and thus are adapted to the ambient temperature, whereas they might not be optimally adapted to novel temperature conditions created by global warming. Although invasive plant species are locally adapted as frequently as native plants are (Oduor et al., 2016), invasive plants may naturally be pre-adapted to a wider range of temperatures (Bradley et al., 2015), and hence warming could enhance invasiveness of these alien plants.

Invasive plant species have often been introduced from more nitrogen-rich habitats and are thus more likely to be adapted to environments with high nitrogen levels (Dostál et al., 2013). A previous study also showed a positive correlation between $\mathrm{N}$ deposition and abundance of invasive plant species at a regional scale (Scherer-Lorenzen et al., 2007). This indicates that increased $\mathrm{N}$ deposition could promote plant invasion (Bradley et al., 2010a). Our meta-analysis tentatively supports this, because we found that the response of invasive plants to increased $\mathrm{N}$ deposition was marginally significantly higher than that of native plants. Our finding is in line with previous cross-species studies
(Scherer-Lorenzen et al., 2000) and also with a previous meta-analysis showing that nitrogen enrichment favoured invasive terrestrial plant species over native terrestrial plants (Gonzalez et al., 2010). A recent study showed that in many grasslands, introduced plant species respond more strongly to nitrogen enrichment than native plant species do (Seabloom et al., 2015). Thus, the idea that invasive plants benefit more from increased nitrogen than native plants do seems to find general support, despite the marginal significance of this difference in our meta-analysis.

While atmospheric $\mathrm{CO}_{2}$ concentration, temperature and $\mathrm{N}$ deposition are likely to further increase in most parts of the world, precipitation is likely to increase in some regions and decrease in other regions (Naz et al., 2016). Moreover, there is a high uncertainty around the predictions of future precipitation levels, and it is likely that the frequency of extremely dry and wet years will increase (IPCC, 2013). Therefore, it is important to distinguish studies that increased from those that decreased the water availability relative to ambient levels (Sorte et al., 2013). Our meta-analysis indicated that invasive plant species tended to take more advantage of higher water availability, but that this difference was not significant. On the other hand, invasive plants tended to be slightly less drought tolerant than native plants, although this was only marginally significant. Sorte et al. (2013) found similar patterns for responses to changes in precipitation between alien and native organisms as we did, and the differences in their metaanalysis were also not statistical significant. The patterns revealed by both meta-analyses were quite similar due to the high degree of overlap in publications used for this global change component (13 out of 16 publications used in our study were also used in Sorte et al., 2013). Generally, invasive plant species tend to use more water than native plant species do (Cavaleri \& Sack, 2010). Consequently, increases in precipitation may favour and, conversely, decreases in precipitation could inhibit invasive plant species more so than native plant species (Bradley et al., 2010b). Such patterns are also in line with the results of several field experiments (Levine et al., 2010; Ziska \& Dukes, 2014). Our finding thus tentatively suggests that invasiveness of many currently invasive alien plants might decrease when the climate becomes drier.

The present meta-analysis has quantitatively summarized the patterns of invasive and native plant species' responses to individual components of global environmental change. However, many of these components change simultaneously, and these changes may additively or interactively impact plant performance (Dukes et al., 2005; Bloor et al., 2010; Dieleman et al., 2012). For instance, elevated $\mathrm{CO}_{2}$ can enhance water-use efficiency 
and thereby increase plant productivity under drier conditions (Blumenthal et al., 2013). On the other hand, warming often reduces soil moisture and increases water use, thus negating the water-saving effects of elevated $\mathrm{CO}_{2}$ (Cantarel et al., 2013). So, while some of the effects of different individual global change components may act in the same direction (Zavaleta et al., 2003), others may act antagonistically (Williams et al., 2007). Despite the potential importance of co-occurring environmental changes, few studies to date (only eight out of the 56 publications included in our meta-analysis) have examined invasive and native species' responses to more than one global change component at a time. Therefore, the question as to what is the relative significance as well as the interactive effects of environmental change components on performance of invasive and native plants remains largely unexplored empirically.

In a summary, our meta-analysis revealed that invasive alien plant species benefited from elevated mean temperature and atmospheric $\mathrm{CO}_{2}$ concentrations more so than native plants. There were similar patterns in response to increased $\mathrm{N}$ deposition and increases in precipitation (although the results were not significant). Among the native species, there was also wide variation in their responses, suggesting that some of them might benefit and expand their ranges. Similarly, among the invasive species, some species might benefit less than others under increased levels of the different global change components. Despite this variation within groups, overall, our findings suggest that global change drivers that create favourable environmental conditions, particularly elevated temperature and atmospheric $\mathrm{CO}_{2}$ concentrations, will further increase the invasiveness of invasive alien plants in the future.

\section{Acknowledgements}

We are very grateful to Dr. Zdravko Baruch Glaser who kindly provided data. We apologize to all those authors whose work we may have missed. Y. J. Liu was funded by a scholarship from the China Scholarship Council (scholarship number 201304910318). A. M. O. Oduor was funded by a Georg Forster Research Fellowship of the Alexander von Humboldt Foundation (grant number 3.4-KEN/1148979 STP). Z. Zhang was supported by a grant from the National Natural Science Foundation of China (grant number 31540051 and 31470560). We thank the editors and three anonymous referees for the valuable comments on improvements of the manuscript.

\section{References}

Ashby WC, Hellmers H (1959) Flowering and growth responses to photoperiod and temperature for six southern California grasses. Botanical Gazette, 120, 151-157.

Bloor JG, Pichon P, Falcimagne R, Leadley P, Soussana J-F (2010) Effects of warming, summer drought, and $\mathrm{CO}_{2}$ enrichment on aboveground biomass production, flowering phenology, and community structure in an upland grassland ecosystem. Ecosystems, 13, 888-900.
Blumenthal DM, Resco V, Morgan JA et al. (2013) Invasive forb benefits from water savings by native plants and carbon fertilization under elevated $\mathrm{CO}_{2}$ and warming. New Phytologist, 200, 1156-1165.

Borenstein M, Hedges LV, Higgins JPT, Rothstein HR (2009) Fixed-effect model. In: Introduction to Meta-Analysis (eds Michael B, Larry VH, Julian PTH, Hannah RR), pp. 63-67. John Wiley \& Sons Ltd, Chichester, UK.

Bradley BA, Blumenthal DM, Wilcove DS, Ziska LH (2010a) Predicting plant invasions in an era of global change. Trends in Ecology \& Evolution, 25, 310-318.

Bradley BA, Wilcove DS, Oppenheimer M (2010b) Climate change increases risk of plant invasion in the eastern United States. Biological Invasions, 12, 1855-1872.

Bradley BA, Early R, Sorte CJB (2015) Space to invade? Comparative range infilling and potential range of invasive and native plants. Global Ecology and Biogeography, 24, 348-359.

Cantarel AAM, Bloor JMG, Soussana J-F (2013) Four years of simulated climate change reduces above-ground productivity and alters functional diversity in a grassland ecosystem. Journal of Vegetation Science, 24, 113-126.

Cavaleri MA, Sack L (2010) Comparative water use of native and invasive plants at multiple scales: a global meta-analysis. Ecology, 91, 2705-2715.

Chamberlain SA, Hovick SM, Dibble CJ et al. (2012) Does phylogeny matter? Assessing the impact of phylogenetic information in ecological meta-analysis. Ecology Letters, 15, 627-636.

Davidson AM, Jennions M, Nicotra AB (2011) Do invasive species show higher phenotypic plasticity than native species and if so, is it adaptive? A meta-analysis. Ecology Letters, 14, 419-431.

Dawson W, Fischer M, Van Kleunen M (2011) The maximum relative growth rate of common UK plant species is positively associated with their global invasiveness. Global Ecology and Biogeography, 20, 299-306.

Dawson W, Rohr RP, Van Kleunen M, Fischer M (2012) Alien plant species with a wider global distribution are better able to capitalize on increased resource availability. New Phytologist, 194, 859-867.

Dieleman WIJ, Vicca S, Dijkstra FA et al. (2012) Simple additive effects are rare: a quantitative review of plant biomass and soil process responses to combined manipulations of $\mathrm{CO}_{2}$ and temperature. Global Change Biology, 18, 2681-2693.

Dostál P, Dawson W, Van Kleunen M, Keser LH, Fischer M (2013) Central European plant species from more productive habitats are more invasive at a global scale. Global Ecology and Biogeography, 22, 64-72.

Dukes JS, Mooney HA (1999) Does global change increase the success of biological invaders? Trends in Ecology \& Evolution, 14, 135-139.

Dukes JS, Chiariello NR, Cleland EE et al. (2005) Responses of grassland production to single and multiple global environmental changes. PLoS Biology, 3, e319.

Egger M, Smith GD, Schneider M, Minder C (1997) Bias in meta-analysis detected by a simple, graphical test. British Medical Journal, 315, 629-634.

Funk JL, Vitousek PM (2007) Resource-use efficiency and plant invasion in lowresource systems. Nature, 446, 1079-1081.

Gonzalez AL, Kominoski JS, Danger M, Ishida S, Iwai N, Rubach A (2010) Can ecological stoichiometry help explain patterns of biological invasions? Oikos, 119, 779-790.

Grotkopp E, Erskine-Ogden J, Rejmánek M (2010) Assessing potential invasiveness of woody horticultural plant species using seedling growth rate traits. Journal of Applied Ecology, 47, 1320-1328.

Gurevitch J, Hedges LV (2001) Meta-analysis: combining the results of independent experiments. In: Design and Analysis of Ecological Experiments (eds Scheiner SM, Gurevitch J), pp. 347-369. Oxford University Press, Oxford, UK.

Heberling JM, Fridley JD (2013) Resource-use strategies of native and invasive plants in eastern North American forests. New Phytologist, 200, 523-533.

Hedges LV, Gurevitch J, Curtis PS (1999) The meta-analysis of response ratios in experimental ecology. Ecology, 80, 1150-1156.

Henry H, William CA (1958) Growth of native and exotic plants under controlled temperatures and in the San Gabriel Mountains California. Ecology, 39, 416-428.

Holland EA, Braswell BH, Sulzman J, Lamarque JF (2005) Nitrogen deposition onto the United States and western Europe: synthesis of observations and models. Ecological Applications, 15, 38-57.

IPCC (2013) Working Group 1, Fifth Assessment Report. Cambridge University Press, Cambridge, UK.

Jia J, Dai Z, Li F, Liu Y (2016) How will global environmental changes affect the growth of alien plants? Frontiers in Plant Science, 7, 1-11.

van Kleunen M, Weber E, Fischer M (2010) A meta-analysis of trait differences between invasive and non-invasive plant species. Ecology Letters, 13, 235-245.

van Kleunen M, Dawson W, Essl F et al. (2015) Global exchange and accumulation of non-native plants. Nature, 525, 100-103.

Koricheva J, Gurevitch J, Mengersen K (eds.) (2013) Handbook of Meta-analysis in Ecology and Evolution. Princeton University Press, Princeton, NJ. 
Koricheva J, Gurevitch J, Gómez-Aparicio L (2014) Uses and misuses of meta-analysis in plant ecology. Journal of Ecology, 102, 828-844.

Leimu R, Mutikainen PIA, Koricheva J, Fischer M (2006) How general are positive relationships between plant population size, fitness and genetic variation? Journal of Ecology, 94, 942-952.

Leishman MR, Thomson VP, Cooke J (2010) Native and exotic invasive plants have fundamentally similar carbon capture strategies. Journal of Ecology, 98, 28-42.

Levine JM, Mceachern AK, Cowan C (2010) Do competitors modulate rare plant response to precipitation change? Ecology, 91, 130-140.

Liu X, Zhang Y, Han W et al. (2013) Enhanced nitrogen deposition over China. Nature, 494, 459-462.

Llorens L, Pe Uelas J, Estiarte M, Bruna P (2004) Contrasting growth changes in two dominant species of a Mediterranean Shrubland submitted to experimental drought and warming. Annals of Botany, 94, 843-853.

Naz BS, Kao S-C, Ashfaq M, Rastogi D, Mei R, Bowling LC (2016) Regional hydrologic response to climate change in the conterminous United States using highresolution hydroclimate simulations. Global and Planetary Change, 143, 100-117.

Oduor AMO, Leimu R, Van Kleunen M (2016) Invasive plant species are locally adapted just as frequently and at least as strongly as native plant species. Journal of Ecology, 104, 957-968.

Paradis E, Claude J, Strimmer K (2004) APE: Analyses of Phylogenetics and Evolution in R language. Bioinformatics, 20, 289-290.

Pearcy RW, Ehleringer J (1984) Comparative ecophysiology of C3 and C4 plants. Plant, Cell \& Environment, 7, 1-13.

Peñuelas J, Filella I, Comas P (2002) Changed plant and animal life cycles from 1952 to 2000 in the Mediterranean region. Global Change Biology, 8, 531-544.

Pimentel D, Zuniga R, Morrison D (2005) Update on the environmental and economic costs associated with alien-invasive species in the United States. Ecological Economics, 52, 273-288.

Poorter H (1993) Interspecific variation in the growth response of plants to an elevated ambient $\mathrm{CO}_{2}$ concentration. Vegetatio, 104-105, 77-97.

R Core Team (2015) R: a language and environment for statistical computing. R Foundation for Statistical Computing, Vienna, Austria. Available at: http:// www.R-project.org/ (accessed 01 October 2015).

Rasband WS (2013) U.S. National Institutes of Health, Bethesda, Maryland, USA. Available at: http://imagej.nih.gov/ij/ (accessed 01 October 2015).

Richards CL, Bossdorf O, Muth NZ, Gurevitch J, Pigliucci M (2006) Jack of all trades, master of some? On the role of phenotypic plasticity in plant invasions. Ecology Letters, 9, 981-993.

Rosenthal R (1979) The file drawer problem and tolerance for null results. Psychological Bulletin, 86, 638-641.

Rustad L, Campbell J, Marion G et al. (2001) A meta-analysis of the response of soil respiration, net nitrogen mineralization, and aboveground plant growth to experimental ecosystem warming. Oecologia, 126, 543-562.

Scherer-Lorenzen M, Elend A, Nöllert S, Schulze E-D (2000) Plant invasions in Germany: general aspects and impact of nitrogen deposition. In: Invasive Species in a Changing World (eds Mooney HA, Hobbs RJ), pp. 351-368. Island Press, Washington, D.C.

Scherer-Lorenzen M, Venterink HO, Buschmann H (2007) Nitrogen enrichment and plant invasions: the importance of nitrogen-fixing plants and anthropogenic eutrophication. In: Biological Invasions (ed Nentwig W), Springer Berlin Heidelberg, Berlin, Heidelberg.

Seabloom EW, Borer ET, Buckley YM et al. (2015) Plant species' origin predicts dominance and response to nutrient enrichment and herbivores in global grasslands. Nature Communications, 6, 1-8.

Sorte CJ, Ibanez I, Blumenthal DM et al. (2013) Poised to prosper? A cross-system comparison of climate change effects on native and non-native species performance. Ecology Letters, 16, 261-270.

Sterne JAC, Egger M (2001) Funnel plots for detecting bias in meta-analysis: guidelines on choice of axis. Journal of Clinical Epidemiology, 54, 1046-1055.

Sterne JAC, Egger M (2006) Regression methods to detect publication and other bias in meta-analysis. Publication Bias in Meta-Analysis: Prevention, Assessment and Adjustments, pp. 99-110. John Wiley \& Sons Ltd, Chichester, UK.

Tilman D (2004) Niche tradeoffs, neutrality, and community structure: a stochastic theory of resource competition, invasion, and community assembly. Proceedings of the National Academy of Sciences of the United States of America, 101, 10854-10861.

Viechtbauer W (2010) Conducting meta-analyses in $\mathrm{R}$ with the metafor Package. Journal of Statistical Software, 36, 1-48.

Vilà M, Espinar JL, Hejda M et al. (2011) Ecological impacts of invasive alien plants: a meta-analysis of their effects on species, communities and ecosystems. Ecology Letters, 14, 702-708.

Webb CO, Donoghue MJ (2005) Phylomatic: tree assembly for applied phylogenetics. Molecular Ecology Notes, 5, 181-183.
Williams AL, Wills KE, Janes JK, Vander Schoor JK, Newton PCD, Hovenden M] (2007) Warming and free-air $\mathrm{CO}_{2}$ enrichment alter demographics in four co-occurring grassland species. New Phytologist, 176, 365-374.

Zavaleta ES, Shaw MR, Chiariello NR, Mooney HA, Field CB (2003) Additive effects of simulated climate changes, elevated $\mathrm{CO}_{2}$, and nitrogen deposition on grassland diversity. Proceedings of the National Academy of Sciences of the United States of America, 100, 7650-7654.

Ziska LH, Dukes JS (eds.) (2014) Invasive Species and Global Climate Change. CABI, Oxfordshire.

\section{Supporting Information}

Additional Supporting Information may be found in the online version of this article:

Materials and Methods S1. List of published studies from which data were extracted. $\mathrm{C}$, elevated $\mathrm{CO}_{2} ; \mathrm{N}$, nitrogen deposition; $\mathrm{P}$, elevated precipitation; $\mathrm{T}$, elevated temperature.

Materials and Methods S2. A phylogenetic tree used in this study and a list of published studies used for resolving polytomies within the initial base tree.

Table S1. Results of a phylogenetically informed meta-analysis of plant species responses to environmental change (i.e. increased and decreased precipitation, elevated temperature, elevated atmospheric $\mathrm{CO}_{2}$ levels, and nitrogen deposition) regardless of a plant origin (alien or native).

Table S2. Results of a phylogenetically informed meta-analysis comparing alien (included both invasive and non-invasive alien plants) and native plant species for differences in response to environmental change (i.e. increased and decreased precipitation, elevated temperature, elevated atmospheric $\mathrm{CO}_{2}$ levels, and nitrogen deposition).

Table S3. Results of a phylogenetically informed meta-analysis of plant species response to environmental change (i.e. increased and decreased precipitation, elevated temperature, elevated atmospheric $\mathrm{CO}_{2}$ levels, and nitrogen deposition) regardless of a plant invasive status (invasive alien or native).

Figure S1. Performance responses (indicated by $\log$ response ratio mean effect sizes) of plant species to drivers of global environmental change (increased and decreased precipitation, elevated temperature, elevated atmospheric $\mathrm{CO}_{2}$ levels and nitrogen deposition) regardless of their origin (i.e. alien and native).

Figure S2. Performance responses (indicated by $\log$ response ratio mean effect sizes) of native (blue symbols) and alien (invasive and possibly non-invasive) plant species (red symbols) to drivers of global environmental change (increased and decreased precipitation, elevated temperature, elevated atmospheric $\mathrm{CO}_{2}$ levels, and nitrogen deposition).

Figure S3. Performance response (indicated by log response ratio mean effect sizes) of plant species to drivers of global environmental change (increased and decreased precipitation, elevated temperature, elevated atmospheric $\mathrm{CO}_{2}$ levels, and nitrogen deposition) regardless of a plant invasive status (i.e. invasive alien and native).

Figure S4. A funnel plot showing the relationship between effect size $(\ln R)$ and the inverse of the standard error (i.e. a test for publication bias). 